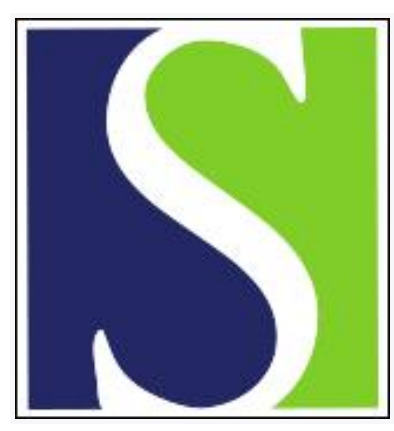

Scand J Work Environ Health 1999;25(6):574-579

https://doi.org/10.5271/sjweh.483

Issue date: Dec 1999

Challenges for indoor environment research in the new office by Schneider T, Skov P, Valbjørn O

Key terms: individual control; individual reaction; psychosocial factor; sick-building syndrome; trade-off

This article in PubMed: www.ncbi.nlm.nih.gov/pubmed/10884156

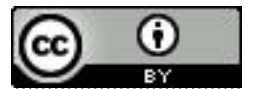




\title{
Challenges for indoor environment research in the new office
}

\author{
by Thomas Schneider, ${ }^{1}$ Peder Skov, ${ }^{2}$ Ole Valbjorn ${ }^{3}$
}

\begin{abstract}
Schneider $T$, Skov $P$, Vaibjørn 0 . Challenges for indoor environment research in the new office. Scand $J$ Work Environ Health 1999;25 (6, special issue):574-579.

This paper discusses new directions for indoor environment research for the following 4 themes: (i) the current change in office work pattern, workplace design, and increasing demands from the work force, (ii) the large individual variation in requirements for optimal conditions pointing at the key factors of individual response and individual control options based on trade-off experiments, (iii) psychosocial factors as determinants of symptoms, comfort, and productivity, and (iv) transient, nonspecific symptoms in the indoor environment, the identification of causes, and long-term consequences.
\end{abstract}

Key terms individual reaction, individual control, psychosocial factors, sick-building syndrome, trade-off.

\section{The future office environment}

The difference between industrial and office-like work environments is becoming less distinct as industry reduces physical and chemical exposures by using cleaner production technologies, automation, and the like. The difference between work and home is also fading as the widespread use of information technology offers the opportunity to work almost anywhere.

As a consequence, an increasing sector of the working population will share the same types of indoor environment exposures. Thus it will become increasingly difficult in population studies to define groups that have a distinctive set of exposure patterns (ie, obtain groups with

Table 1. Changes in work pattern in the next millenium. Adapted from Wouters \& Van Bommel (1).

\begin{tabular}{lll}
\hline & Traditional & Trends \\
\cline { 2 - 3 } Work pattern & $\begin{array}{l}\text { Routine } \\
\text { Individual assignment }\end{array}$ & $\begin{array}{l}\text { Creative } \\
\text { Groups and project } \\
\text { teams } \\
\text { Interactive }\end{array}$ \\
Workplace & $\begin{array}{l}\text { Isolated } \\
\text { One type }\end{array}$ & $\begin{array}{l}\text { Different types for } \\
\text { different tasks } \\
\text { "Continuously" }\end{array}$ \\
Occupation & $\begin{array}{l}9-17 \text { hours } \\
\text { Own workstation or } \\
\text { room }\end{array}$ & $\begin{array}{l}\text { Different or shared } \\
\text { workplaces }\end{array}$ \\
Location assignment & On the basis of status & On the basis of tasks \\
\hline
\end{tabular}

small within-group and large between-group variability in exposure).

The needs and demands of office work force are changing. Many tasks will be solved interactively by project teams, and offices will be designed to support the social communication necessary for interactive projects. On the other hand, people need to work in isolation for some periods. The trend is away from personal offices towards rooms that will be available whenever someone has a need. Table 1 summarizes these changes in work pattern. Future workplaces will be designed to support the requirements inherent in these changes. The new work patterns will be introduced in both old and new buildings, which offer different possibilities for fulfilling the new requirements. We do not expect that the resulting work conditions will lead to major changes in the physicochemical exposure levels in offices, but the psychosocial and organizational conditions under which occupants are exposed may change. One of the challenges for indoor environment research will be to evaluate the impact of new work conditions and building design on health, comfort, and productivity. Future field studies should, as a consequence, record specific work conditions and the type of jobs as a possible explanatory variable for responses, and they should also include living conditions and leisure-time activities.

$1 \quad$ National Institute of Occupational Health, Copenhagen, Denmark.

2 Occupational Health Clinic, Roskilde County Hospital Køge, Køge, Denmark.

3 National Building Research Institute, Hørsholm, Denmark.

Reprint requests to: Dr T Schneider, National Institute of Occupational Health, Lersø Parkalle 105, DK-2100 Copenhagen, Denmark. [E-mail: ts@ami.dk] 


\section{New ways to consider the indoor environment}

\section{Physical factors}

International standards provide specific comfort guidelines for average thermal conditions for given clothing and physical activities. However, there are major individual differences in the perception of thermal conditions, especially when it comes to accepting light thermal stress (2). Thermal conditions can influence the productivity of office workers (3), and individual control around average thermal neutrality has been found to improve productivity slightly (2). Thus individual control of thermal conditions will be important for achieving optimal conditions.

Acoustic conditions should facilitate communication if information is needed for the performance of tasks, but it should suppress unwanted disturbance, distracting information, or noise. It is well known that some groups of people are noise tolerant, being able to adapt psychologically to noise, while others are noise sensitive (4). Workers thus should be given the possibility to choose quiet work conditions if the task requires it.

Detailed guidelines exist for artificial lighting for different tasks, including work with visual display units (VDU), in order to satisfy performance requirements. Daylight and color can influence comfort, mood, and social behavior $(5,6)$. Although international guidelines for daylight and color have not yet been agreed on, and may never be, due to individual and cultural differences, it is prudent to provide access to daylight and individual control of lighting. This requirement is partly at odds with systems for the automatic control of lighting for the purpose of energy saving, as such systems may override individual control.

These few examples serve to illustrate that optimal conditions will vary around a group average, depending on the workers and their tasks. Each person should therefore be given the possibility of individual influence and control, and the control should be easy to use. This is a challenge to building designers. Another challenge is for building managers. Traditionally they have focused on building technology, operation, and maintenance. In the next millennium this focus must be shifted to the workers, as they will give priority to self-development, individuality, flexibility, and participation, combined with self-determination and control of the total work environment.

\section{Odor}

The perception of odor is one of the most important factors triggering complaints about the indoor environment. Experiments with odor panels evaluating emissions from different building materials have shown that diluting the concentration increases odor acceptability differently for different odors and that some odors remain unacceptable at all dilutions (7). There are no simple models to predict how odorous volatile organic compounds (VOC) combine into a perception and not even into odor intensity (8). Thus no generally applicable transformation is yet known for transforming a panel voting into a quantity that can be handled like a concentration that, for example, would follow the usual dilution laws and be used for simple design criteria for odor control by ventilation.

The interaction between odor and sensory irritation (9) needs to be studied. We also recommend that the psychological effects of weak odors be investigated. The challenge will be to perform the studies under normal work conditions to reflect the complexity of most officeenvironment scenarios.

\section{Perceived cleanliness}

While cleaning is performed for reasons of hygiene, safety, esthetics, and surface care, the importance for nonspecific symptom prevalence is not clear. Relations have been found between surface dust or dust constituents and the prevalence of symptoms $(10,11)$, but a causal connection with specific components has not yet been found, except for some specific allergens. Only little is known about how perceived cleanliness relates to the physical quantity of dust on surfaces (12), and whether or not the perception of dust or cleanliness per se can result in biological reactions has not been studied. Surface dust is usually perceptible (visual, tactile), and it is thus difficult to avoid information bias in epidemiologic studies. Dust on surfaces is a potential secondary dust source and should be controlled by cleaning. Guidelines have been proposed for the degree of surface cleanliness based on field data of what is practically achievable (13). Future studies on the relation between surface dust concentrations and perception and between dust composition and health may show whether or not the guidelines need to be adjusted.

\section{Trade-off}

A person who is working in an office space that is too warm and wants to increase air cooling, which however would increase noise level, has to balance a reduction in thermal discomfort against an increase in noise. Such preferences are studied in trade-off experiments, which result in iso-annoyance curves in the multidimensional space of exposure factors. Trade-off experiments have been made under uncomfortable (tropical) conditions that could relate temperature preference level to noise preference level and even to relative air velocity and daylight admission (14). Trade-off relations are important because they are needed as a basis for improved 
prioritizing and for the design of work environments in cases in which compromises have to be made in building design for economic or other reasons. In addition, since optimal conditions are not constant but vary with the task and person, trade-off relations play a role in the choices people have to make every day regarding the adjustment of indoor environment parameters.

\section{Psychosocial factors}

In an editorial Berglund \& Job (15) noted that the scientific community had neglected to consider adequately the role of psychological effects on adverse environmental impacts (both ambient and indoor) even though there was a general acceptance that effects were likely to exist. In a companion editorial, Moghissi \& Berglund (16) did not doubt that reactions to environmental pollution, real or imagined, could have an impact on the human psyche and thus physiological functions. They welcomed “. . . studies dealing with behavioral consequences of exposures to non-existing or insignificant pollution which, however, is believed to exist by a segment of the population". Psychosocial factors should be studied also since they are becoming more important on a relative scale because exposures to physical agents and air contaminants have been reduced due to increased awareness about building construction, building materials, and the like. Psychosocial factors may even be the dominating determinant of symptoms, comfort, and productivity (17). There is yet no generally accepted theoretical framework for formulating hypotheses on how psychological factors interact with other office-environment factors.

Comparison of the relative significance of symptom prevalence, comfort, and the productivity of physicochemical factors with those of psychosocial factors should be made with caution because of estimation uncertainty. In industrial epidemiology there has been considerable attention focused on how uncertainty in the estimation of exposures to physical and chemical factors attenuates or amplifies exposure-response relations (18). In epidemiologic studies of the indoor environment this problem has not been sufficiently addressed even though physicochemical and psychosocial factors are measured with fundamentally different methods and all too often with a greatly different level of detail.

There is a need for validated questionnaires on psychosocial factors $(19,20)$. A rather extensive questionnaire is needed for the purpose of identifying the specific psychosocial problems. A short questionnaire is needed that can be used at an early stage in the stepwise approach to solve indoor environmental problems. The questionnaires should mirror the new requirements (ie, the possibility for self-determination and control of the total work environment).

\section{Sick-building syndrome and a time for change!}

The possible health effects of the indoor work environment range from allergy to cancer; however, we will only discuss the transient, nonspecific symptom complaints among office workers that are temporally related to a building or specific areas in a building. Allergic reactions have been excluded.

\section{Symptoms}

The term sick-building syndrome (SBS), characterizing the occurrence of an increased prevalence of nonspecific symptoms among occupants in certain buildings, was coined at a meeting of the World Health Organization in 1982 (21). The term has served well, as it became a frame of common reference for physicians and engineers and brought the message across to politicians that buildings could be problematic. As a result, significant progress has been made in reducing physical, chemical, and biological exposure factors. However, the sick-building syndrome is a diffuse concept. It is not a disease entity, and the terminology used in relation to it has not been consistent. The number and type of nonspecific symptoms used under the concept have been a theme with variation in the literature (22), but the most frequently investigated symptoms are irritation of the mucous membranes of the eyes, nose, and throat and general symptoms, such as fatigue, tiredness, or headache. Some researchers also include dry and irritated skin. The term sick-building syndrome indicates that it is a medical syndrome, but it has not been possible to apply this diagnosis to individual persons according to specific biological markers and symptom criteria (22).

As we have learned more about what can, or rather what cannot, explain symptom prevalence for the sickbuilding syndrome, it has become evident that the time for its traditional interpretation has run out: the term sickbuilding syndrome should not be brought into the next millennium. In line with others (23), we suggest using the more conservative, less appealing, more descriptive "transient nonspecific symptoms in the indoor environment". Future research should focus on the frequency and intensity of the single symptoms and groups of related symptoms (eg, mucous membrane irritation of the eyes, nose and throat).

\section{Factors related to transient, nonspecific symptoms in the indoor environment}

Epidemiologic research has identified several factors associated with nonspecific symptoms in the indoor environment (24). A low ventilation rate and a slightly raised temperature have been associated with symptoms, but most factors are of a descriptive nature, like "air-conditioning" and "carpets", and are at best proxies for causal exposures. Other factors have to do with work tasks and 
psychosocial aspects of work, and individual factors like gender and allergic disposition. With the exception of formaldehyde, which today is mostly found in low concentrations, indoor environment research has not been able to demonstrate a causal relationship between the specific indoor air contaminants normally found in the indoor environment and the occurrence of nonspecific symptoms. Different mixtures of volatile organic compounds and biological components of dust have been candidates for some years, but they have not consistently been associated with nonspecific symptoms, in spite of the ever more sophisticated measurements of pollutants. Furthermore, the eye and nose irritation thresholds are orders of magnitude above the concentrations generally found in the indoor environment (25). It is therefore difficult to explain why any known and presently measurable airborne chemical in the common indoor environment per se may cause sensory irritation of the eyes, nose, or throat. Other mechanisms must therefore be considered. Future epidemiologic and experimental research should change the usual design and methods and focus on the incidence and course of the nonspecific symptoms in different indoor environments. This change would call for longitudinal studies with a duration exceeding 1 year. Such studies will also provide the opportunity to investigate long-term consequences of having repeated, transient nonspecific symptoms: Will it cause symptoms to become more persistent? Will it have consequences for absenteeism, medication, social behavior, and productivity?

Associations have often been found between psychological factors such as stress and mucosal irritation and general symptoms. We therefore propose studies to reveal how and to what degree psychosocial factors influence the thresholds of sensory irritation and the prevalence and intensity of transient, nonspecific symptoms.

\section{Objective and subjective measures of transient, nonspecific symptoms}

Our knowledge of the mechanisms behind nonspecific symptoms is limited, and there are, for example, no objective measures available to tell if a person suffers from eye or nose irritation or not. However, on a group level, associations have been found between objective changes in the eyes and work-related eye symptoms among office workers $(26,27)$.

Methods are needed for the noninvasive measurement of sensory irritation and changes in the mucous membrane. The physiological states measured should have low within-person variability to be useful. These methods could then be used in longitudinal studies for determining if and how measurable changes in the mucous membrane lead to chronic effects.

There is a need to reduce the number of questionnaires for measuring subjective symptoms to a few validated and comparable questionnaires, both for research and, especially, for practical attempts to identify and solve indoor environmental problems in office buildings. It is of particular importance to have a large common data base on basic prevalences obtained with the respective questionnaires for reference populations.

\section{Somatization}

Somatization is the process of organically manifesting and expressing cognitive and emotional disturbances through bodily symptoms. People can employ somatization as a means of communication or as a coping strategy, and somatization can play a major role in determining the degree of illness for many sufferers of nonspecific symptoms (28). The role of somatization in the dynamics of perception and the reporting of symptoms and how somatization relates to the way indoor environment problems are handled should be studied further.

\section{General discussion}

The learnings from field and laboratory studies of associations between perceptions and symptoms and measured exposures and descriptive building factors have been made operational. A report from Nordtest (29) proposes what should be understood by low, medium, and high exposures for several indoor environment factors. These levels were further defined in a Danish design guide and successfully used in a large European investigation (17). Rolloos and his co-workers (30) proposed a classification system based on exposure levels combined with descriptive design elements, and Seppänen (31) developed a detailed checklist for office building design based on data from the "Indoor Air '93" conference. There is thus close to sufficient knowledge to provide general recommendations for designing building climates, recommendations which satisfy the basic needs for groups of occupants. On the other hand, there is limited knowledge on the impact if some conditions are out of order or cannot be fulfilled for economic reasons. In addition, as the demands of the work force increase, in response to increased individualism, solid scientific data also need to be generated as a basis for designing individual control. Easy-to-use individual control technology will become a key concept for achieving the best possible conditions for each person.

The trade-off experiment is an important method for studying combined exposures. However, since there is an almost unlimited number of possible combinations, studies should try to uncover the underlying mechanisms. The role of participatory approaches to problem solving needs to be studied also (20). 


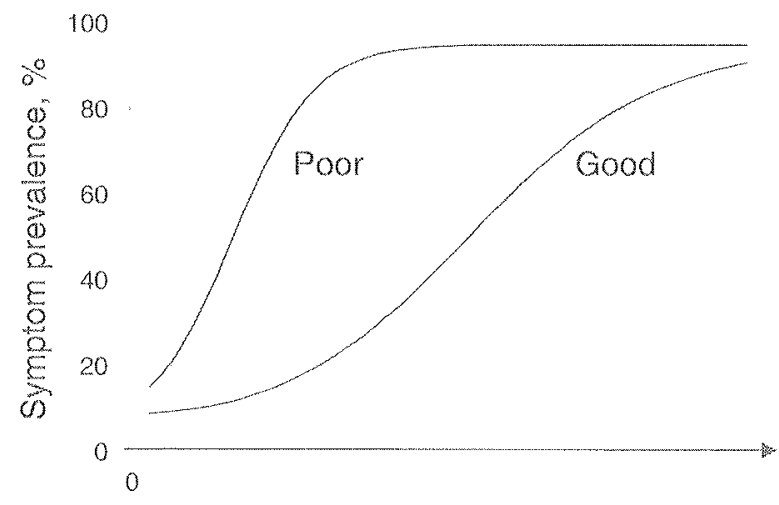

\section{Sum of physicochemical exposures}

Figure 1. Hypothesized dose-response curves for exposures and symptom prevalence for a group of occupants. The two curves represent poor and good psychosocial conditions and the possibility of coping with all work conditions. Adapted from Valbjørn et al (32).

The complexity involved when multifactorial causes of symptoms are interpreted is illustrated in figure 1, adapted from the paper by Valbjørn et al (32). Hypothetical relations are drawn between symptom prevalence and the sum of exposure to physicochemical factors. The two (logistic) curves represent poor and good psychosocial conditions, including the ability of each person to cope with the situation and to optimize climatic conditions. The curves predict that when the sum of physicochemical exposures is high, a reduction in psychosocial load does not make much difference to the reported prevalence. The curves also predict that, at low physicochemical exposures, priority should be given to psychosocial factors.

We have formulated a (nonexhaustive) list of research topics. As a concluding remark we would like to stress that real progress in problem solving to create healthy, comfortable, and productive office environments can only be made by thinking in terms of total workplace performance, in which buildings, the occupants, and their tasks perform as a functional unit (33).

\section{References}

1. Wouters M, Van Bommel W. The many faces of the office. Int Light Rev 1998;981:22-5.

2. Wyon D. Individual microclimate control: required range, probable benefits and current feasibility. In: Yoshizawa S, Kimura K, Ikeda K, Tanabe S, Iwata T, editors. Proceedings of Indoor Air '96'; vol 1. Nagoya (Japan): Tokyo Institute of Public Health, 1996:1067-72.

3. Wyon DP. Thermal effects and productivity. In: Seppänen O, Ilmarinen R, Jaakkola JJK, Kukkonen E, Säteri J, Vuorelma H, editors. Proceedings of Indoor Air '93; vol 6. Helsinki: Helsinki University of Technology, 1993:3-13.

4. Cantor D, Stringer P, editors. Environmental interaction. Lon- don: Surrey University Press, 1975.

5. Küller R, Wetterberg L. Melatonin, cortisol, EEG, ECG, and subjective comfort in healthy humans: impact of two florescent lamp types at two light intensities. Light Res Technol 1993;25:71-80.

6. Küller R, Lindsten $\mathrm{K}$. Health and behaviour of children in classrooms with and without windows. J Environ Psychol 1992:12:305-17.

7. Knudsen HN, Kjaer U, Nielsen PA, Wolkoff P. Sensory and chemical characterization of VOC emissions from building products: impact of concentration and air velocity. Atmos Environ 1999:33:1217-30.

8. Wolkoff P. 1999. How to measure and evaluate volatile organic compound emissions from building products: a perspective. Sci Total Environ 227:197-213

9. Dalton P, Wysocki CJ, Brody MJ, Lawley HJ. The influence of cognitive bias on the perceived odor, irritation and health symptoms from chemical exposure. Int Arch Occup Environ Health 1997;69:407-17.

10. Skov P, Valbjørn O, Pedersen BV, Danish Indoor Climate Study Group. Influence of indoor climate on the sick building syndrome in an office environment. Scand J Work Environ Health 1990;16:363-71.

11. Gyntelberg F, Suadicani P, Nielsen JW, Skov P, Valbjørn O, Nielsen PA, et al. Dust and the sick building syndrome. Indoor Air 1994;4:223-38.

12. Kildes $\varnothing$ J, Vallarino J, Spengler JD, Brightman HS, Schneider T. Dust build-up on surfaces in the indoor environment. Atmos Environ 1999;33:699-707.

13. Schneider T, Løbner T, Nilsen SK, Petersen OH. Quality of cleaning quantified. Build Environ 1994;29:363-7.

14. Santos AMB, Gunnarsen LB. Optimizing linked pairs of indoor air parameters. In: Raw G, Aizlewood C, Warren P, editors. Proceedings of Indoor Air'99; vol 3. London: Construction Research Communications Ltd, 1999:191—6.

15. Berglund B, Job RFS. Editorial: the psychology of reactions to environmental agents. Environ Int 1996;22:1-2.

16. Moghissi AA, Berglund B. Editorial; psychological impact of environmental pollution. Environ Int 1996;22:2.

17. Valbjørn O, Valbjørn L, Pedersen JM, Petersen BV, Skov P. Psycho-social conditions and indoor climate in three european office buildings. In: Maroni M, editors. Proceedings of Healthy Buildings '95; vol 3. Milano (Italy): The University of Milano, 1995;1475-80.

18. Loomis D, Salvan A, Kromhout H, Kriebel D. Selecting indices of occupational exposure for epidemiologic studies. Occup Hyg 1999;5:73-91.

19. Jaakkola JJK. The office environment model: a conceptual analysis of the sick building syndrome. Indoor Air 1998;suppl 4:7-16.

20. Lahtinen M, Huuhtanen P, Reijula K. Sick Building Syndrome and psychosocial factors - a literature review. Indoor Air 1998;suppl 4:71-80.

21. World Health Organisation (WHO). Indoor air pollutants: exposure and health effects. Copenhagen: WHO Regional Office for Europe, 1983. EURO reports and studies 78.

22. Thörn $\AA$. The sick building syndrome: a diagnostic dilemma. Soc Sci Med 1998;47:1307-12.

23. Bardana EJ. Sickbuilding syndrome - a wolf in sheep's clothing. Ann Allergy Asthma Immunol 1997;79:283—94.

24. Mendell MJ. A review and summary of the epidemiological literature. Indoor Air 1993;3:227-36.

25. Wolkoff P, Clausen PA, Jensen B, Nielsen GD, Wilkins CK. Are we measuring the relevant indoor pollutants? Indoor Air 
1997;7:92-106.

26. Franck C, Bach E, Skov P. Prevalence of objective eye manifestations in people working in office buildings with different prevalence of the sick building syndrome compared with the general population. Int Arch Occup Environ Health 1993;65:65-9.

27. Muzi G, dell'Omo M, Abretti G, Accattoli P, Fiore MC, Gabrielli AR. Objective assessment of ocular and respiratory alterations in employees in a sick building. Am J Ind Med 1998;34:79-88.

28. Ford CV. Somatization and fashionable diagnoses: illness as a way of life [review]. Scand J Work Environ Health 1997;23 suppl 3:7-16.

29. Kukkonen E, Skåret E, Sundell J, Valbjøm O. Indoor climate problems: investigation and remedy. Espoo (Finland): Nordtest, 1993. NT techn report 204
30. Rolloos R, Cox C. Classification of performance criteria for office environment. In: Bánhidi L, Farkas I, Magyar Z, Rudnai $P$, editors. Proceedings of Healthy Buildings '94; vol 2. Budapest: Technical University of Budapest, 1994:279—86.

31. Seppänen $O$. How to make a healthy building. Summary of Indoor Air '93. In: Bánhidi L, Farkas I, Magyar Z, Rudnai P, editors. Proceedings of Healthy Buildings '94; vol 3 Budapest: Technical University of Budapest, 1994:36-41.

32. Valbjørn O. Important aspects of building design basedon studies of exposures and their effects. In: Yoshizawa S, Kimura K, Ikeda K, Tanabe S, Iwata T, editors. Proceedings Indoor Air '96; vol 3. Nagoya: Institute of Public Health, Tokyo, 1996:729-34

33. Aronof S, Kaplan A. Total workplace performance: rethinking the office environment. Ottawa (Ontario, Canada): WDL Publications, 1995. 